\title{
Analyzing media discourse on the development of the National English Ability Test (NEAT) in South Korea
}

\author{
Dongil Shin(D)
}

\author{
Correspondence: shin@cau.ac.kr \\ Department of English Language \\ and Literature, Chung-Ang \\ University, 84 Heukseok-ro, Seoul \\ 06980, South Korea
}

\begin{abstract}
The purpose of this study is to analyze newspaper articles from three publications (Chosun Ilbo, Donga Ilbo, and JoongAng Ilbo) regarding a newly developed highstakes English test in South Korea, the National English Ability Test (NEAT), from the viewpoint of critical discourse analysis. All of the articles were collected from online archives, and most were published between 2007 and 2012. The events surrounding the development of the test were analyzed from three dimensions: textual, discursive, and social. It was found that NEAT-related media discourse was formulated in terms of technology-focused, economic (private education expenditure), or utilitarian (the benefits of a domestic "Korean" test) practice. These discursive events were implicitly connected to the cultures of "technopoly" and "teach-to-the-test," both of which were exploited to silence the voices of diverse groups in the English language education community.
\end{abstract}

Keywords: Media discourse, Critical discourse analysis, Social dimension of language testing, National English Ability Test (NEAT) in Korea

\section{Introduction}

Traditional research on language testing viewed it as a psychometric exploration that set language knowledge as a test construct (McNamara \& Roever, 2006); however, in recent years, a values-based social discourse on professionalism, ethics, fairness, and social justice in language testing has also been flourishing. This socio-humanities discourse includes both macro- and micro-language testing as well as integrates testing issues with sociopolitical variables (McNamara, 2001; McNamara \& Roever, 2006).

As researchers come to pay more attention to the social dimension of language testing, they take an increasing interest in its social discourse outside of academic environments. Much of the discourse either justifying or opposing the enforcement, preparation, and use of high-stakes language tests is created and/or reproduced in the media. As media pressure often effectively leads to the success of innovation in education reforms (Crawford, 2004; Gonzalez-Carriedo, 2014; Yemini \& Gordon, 2017), the necessity of high-stakes language tests is also well covered in terms of "technologism," laissez-faire market-driven attitudes, and quantitative utilitarianism. As Shohamy (2001, p. 63) pointed out, however, the discourse on the development and use of a high-stakes test can be explicit in one context but ambiguous and contradictory in another. In particular, when a test is politically

(C) The Author(s). 2019 Open Access This article is distributed under the terms of the Creative Commons Attribution 4.0 International License (http://creativecommons.org/licenses/by/4.0/), which permits unrestricted use, distribution, and reproduction in any medium, provided you give appropriate credit to the original author(s) and the source, provide a link to the Creative Commons license, and indicate if changes were made. 
planned and rushed into use without sufficient public debate, the media can exaggerate its meaning in inappropriate ways, distorting or misinterpreting its purposes or expectations.

In this spirit, the present study aims to analyze newspaper articles on the National English Ability Test (NEAT) in Korea-a homegrown, newly developed, and currently suspended English proficiency test-using critical discourse analysis (CDA) to understand the media pressure for the development of high-stakes language testing. The media discourse on the government-led English proficiency test arose after the TOEFL crisis ${ }^{1}$ in 2007. The media's uproar for homegrown English proficiency tests with global competence escalated, with the criticism leveled that Koreans spend more than 10 billion won, or 10.7 million dollars, annually on TOEFL and TOEIC application fees. As the media often play an important role in enabling "think tanks to get their ideas into the education policy arena" (McDonald, 2014, p. 853), the stakeholders of local English tests quickly accessed the media to influence policy debates. In 2008, the Presidential Transition Committee officially announced the development of a new English proficiency test, tentatively called "Korean TOEFL."

With great fanfare, the test, named NEAT later, was developed and trialed as a mandatory national test over the years. The existing English subject test within the College Scholastic Ability Test (CSAT) only assessed listening and reading skills, so it was announced that NEAT, which also additionally assesses speaking and writing skills, would replace the English test in the CSAT. There were strong voices in the public sphere championing NEAT for the positive washback effect. However, the media was also diligent in reporting on the concerns and problems faced during the test development stage, such as excessive private spending on NEAT preparation. Politicians' apprehension about public opinion as well as flagging media coverage led to the abrupt termination of the full administration of the test (Lee \& Lee, 2016; Whitehead, 2016). The plan to use NEAT as a mandatory national test in public schools was suspended by the subsequent government in 2014 due to the issues reported in the media: lack of awareness and practicality.

The present study examines how the media intervened in the initial stage of development of a newly planned test. The high-stakes English test, NEAT, quickly appeared in the limelight and slipped away abruptly, but it has been the subject of little scholarly work. Alongside the evaluation of sociopolitical contexts, it is important to discuss media involvement in the test development, as the validation debate (Bachman \& Palmer, 2010; McNamara \& Roever, 2006) cannot be separated from the media-embedded social contexts. The media, in which test-driven policies are articulated, serves as an arena in agenda setting in terms of sociopolitical discourses, but there is little literature on the critical analysis of media discourse in the field of language testing. Future research works could be planned on how the media legitimizes or challenges stakeholders' interests in the suspension stage of the test.

\section{Media discourse on language testing}

This study was motivated by three previous studies. The first was that of Block (2002) on "McCommunication" in language education, conceptually based on Ritzer's (2000) "McDonaldization." Block claimed that expert systems for "verbal hygiene" (Cameron, $1995,2000)$ led to the processes of language standardization, sociolectalization (development of in-group language), and prescriptivism and that modernized education in communicative competence did not fully allow for diversity and difference among languages and groups of language learners. He stated that communicative acts in the field of second language education were being McDonaldized and that the verbal hygiene 
practices were reflected in the context of developing and expanding high-stakes tests, as social interaction in multifaceted language performance is ignored in the effort to transform language into a set of testable techniques. In this perspective, even uncontrollable aspects of language skills tend to be controlled, thus emphasizing quantification (Block, Gray, \& Holborow, 2012; Tan \& Rubdy, 2008).

The second study motivating this research was on the social dimension of language testing, by McNamara and Roever (2006), who claimed (pp. 1-2) that professional practice in language testing focuses on discrete language knowledge to be measured, leading to an overdependence on psychometrics such as bias analysis or differential item functioning. Their reviews of historical precedents found that social value rather than psychometric accuracy determined the valid use of language tests. McNamara and Roever (2006) argued that even often-cited validity theories (e.g., in Messick, 1989 or Kane, 2001) inappropriately conceptualized or elided the social dimension of language testing. From this perspective, it appears inevitable that tests (constructs) will be politicized in social contexts: a test exists because of sociopolitical forces.

The sociopolitical issues can be seen in the recent discussion of language testing as a concept and a practice in related academic discourses (e.g., Fulcher, 2009; Fulcher \& Davidson, 2007; Hamp-Lyons, 2000; Shohamy, 2001). Some of these studies have demonstrated how an influential test can be used as a disciplinary tool or means of exerting power. For example, Shohamy (2001), citing Foucault (1975, p. 184), stated that test-takers can be "quantified, classified, and punished" and argued that centralized systems force different learning paths to conform to specific standards by imposing powerful tests. However, she simply dichotomized the members of a testing society into tester vs. tested and did not consider the multifaceted power of testing or its poststructuralistic meanings in different social contexts. Menken (2008) criticized New York City's use of high-stakes tests under the federally enforced No Child Left Behind (NCLB) Act in the US. Menken used field data to illustrate that such tests put minorities, immigrants, second-language learners, or low-income students at a disadvantage, thus ignoring their linguistic human rights and basic educational rights. All languages other than English have received steadily decreasing interest as test subjects. Additionally, the streamlined language, denuded of social context, that appears in big tests can often lead to the neglect of various teaching and learning goals. In this regard, widespread use of standardized testing can promote the inappropriate advent of a standardized language system. Considering that Menken's analysis was based on a multicultural and multilingual country (the US), her results are not easily generalizable to other educational contexts; nevertheless, her study signifies the necessity of examining the social value of established and new high-stakes tests.

Finally, this study adopts Fairclough's $(1995,2005)$ media discourse analysis as a research method. Researchers in language testing can of course approach actual test-users (such as students and teachers) to ask questions or observe their behaviors; however, the media has a discursively meaningful influence on test-users' perceptions of testing. All media act as agents of discourse in that they employ sociopolitical practices to influence everyday knowledge or belief systems (van Dijk, 1997). Newspaper texts and images take a position but also constitute the discourse of social observation in specific arenas. Discourses are often legitimized or challenged against the status quo, putting the social practice discourse into action (Fairclough, 1992). This study employs a CDA framework (Fairclough, 1992, 1995, 2005) to analyze newspaper media 
surrounding NEAT. In the framework of CDA, texts and images disseminated by the media are not value neutral but rather function as acts of discourse that influence sociopolitical practice.

The following is a brief description of the three-step (textual, discursive, social practice) analysis in CDA. The first step involves the study of the linguistically analyzable texts, describing how media constructs discourse structure in texts by strategically selecting specific vocabulary, sentence formats, and cohesive devices. The second step involves examining the production, consumption, and interpretation of texts. It not only explores the interdiscursivity of texts by identifying how genres, discourses, and styles are articulated in orders of discourse but also uncovers the intertextual chain across different discursive events. In the last step, (the subsequent discursive effect of) social practice is discursively explored: institutions, power relationships, culture, and day-to-day hegemony justified and cemented, usually implicitly. Social theories are often applied here in analyzing ideological conflicts or consequences.

Fairclough's frameworks "connect microlinguistic analysis to analysis of social practice (intermediate analytical level) and analysis of social structures (macro-analytical level)... particularly relevant to the recent focus in applied linguistics on analysis of the global spread of neoliberalism and its incursion in education" (Lin, 2014, p. 218). It is, however, a highly complicated analysis model, and the procedure of textual analysis, which focuses on particular lexical and grammatical features, is criticized for lack of impartiality, or "ad hoc bricolage" (Widdowson, 1998, p. 136). Widdowson $(1998,2005)$ questions if the small selection of linguistic concepts forms a legitimate foundation for the ideological meanings in the text. A corpus-based methodology is then drawn upon by recent CDA researchers (Baker, Gabrielatos, \& McEnery, 2013; Cheng, 2013) to solve the problem of openness to bias or "to strengthen the systematicity of the interpretive reconstructive procedures by providing evidence on the range of semiotic resources" (Lin, 2014, p. 226).

It should be noted, however, that the outspoken critics of CDA, including Widdowson, do not reject the possibility that lexical and grammatical items genuinely have an ideological valency (Widdowson, 1998), and that the claim being made on the randomness in the selection of CDA data is intuitively argued by them (Breeze, 2011). As far more methodical and analytical attention must be paid to CDA researchers' interpretative procedures, Fairclough's dialectical-relational approach is still regarded by various academic fields as a tool for meaningful discussion of politicized media discourse (Blackledge, 2005; Li, 2009; Lin, 2014). In Korea, for example, in analyzing the TOEFL crisis as publicized by local newspapers (Chosun Ilbo and Donga Ilbo) in 2007, (Shin, 2012). successfully drew on the conventional CDA analytic framework and discussed the chaotic circumstances that characterize TOEFL-taking practices in Korea. The present study can be considered an extension of that analysis. Since NEAT was eventually introduced as a domestic solution to the TOEFL crisis in Korea, the social discourse surrounding NEAT after its introduction in 2007 needs to be explored, given that the media's role in constructing social discourse may help reshape the current practice and direction of testing.

\section{Research method}

\section{Research materials}

This analysis examined NEAT-related articles disseminated in publications produced by three major Korean newspapers, Chosun Ilbo, Donga Ilbo, and JoongAng Ilbo. ${ }^{2}$ All the 
publications were searched using archives provided by the Korean Studies Information Service System (http://kiss.kstudy.com). The scope of analysis was restricted to content appearing between December 21, 2003, and August 31, 2012. (After the 2007 TOEFL crisis, the number of articles had massively increased on domestic tests, government involvement in test development, and NEAT.). Forty-seven articles were analyzed in this study: 15 from Chosun Ilbo, 20 from JoongAng Ilbo, and 12 from Donga Ilbo.

\section{Analysis}

As previously mentioned, this study employed Fairclough's (2005) CDA as an analytical framework, focusing on identifying social practices introduced and sustained by NEAT-related discourses. First, textual analysis of vocabulary and syntax was conducted, mostly by examining the re-wording of terms with similar meanings and occurrence of the same words. Next, the analysis explored how different publications varied in their coverage of NEAT and related topics and whether connections and interdependencies among columns, editorials, and news stories could be identified. For example, one article in Chosun Ilbo employed market-friendly terms such as "demand" and "supply" in the first (topic) sentence of a paragraph, while the remaining sentences supported the topic sentence. The article alluded to NEAT as a "solution" to the TOEFL "crisis," using terms such as "demand," "effectiveness," and "domestic test," prompting readers to align with the article's ideological position. This case reflects the news media's strategy of structuring a system of statements as discourse by using the same tone across editorials, interview quotes, or reader contributions.

\section{Results and discussion}

Texts in three newspapers

In articles on the 2007 TOEFL crisis, Chosun Ilbo selected words suggestive of market principles and denigrated the market competitiveness of "domestic" English proficiency tests, ideas also supported by Donga Ilbo (Shin, 2012). Chosun Ilbo was the first source to highlight government involvement in a newly developed English proficiency test and ran an article on July 31, 2007, titled, "Any problems? Concerns of increasing private education and doubtful usefulness outside Korea." The article contained several negatively oriented words and phrases, such as "a significant number of parents are worried," "even government is doing business," "only good for publishing companies and private institutes," "impossible," "insufficient human resources," "unrealistic," "only for domestic use," "failed attempt," and "doubts on whether government should again get involved in education." Subsequent articles published on January 23 and 24, 2008, used neutral wording to refer to a press release issued by the Ministry of Education ${ }^{3}$ about government-led test development, but an April 29 article heavily criticized the test for technical issues, identifying problems with prerequisites such as "the iBT test's large-scale server," "one million people's simultaneous connection to the server," "complex requirements for a firewalled computer to prevent hacking," as well as issues with "doubts over whether all facilities can be equipped over the next four years." While the article did offer certain solutions to the TOEFL crisis (based on interviews with TOEFL development and enforcement representatives) such as "increasing the number of test administrations ... and the item bank's capability to five times the number of regular test items," the article also pointed out another 
technological issue, related to "maintaining the same levels of item difficulty among parallel forms of testing." The articles re-emphasized the technological aspects of English proficiency testing by quoting statements made by the Ministry about the issues of raters, rater training, and rating reliability.

Donga Ilbo had already mentioned the importance of a government-led English proficiency test before the 2007 TOEFL crisis. An article dated October 10, 2006, issued a specific plan for English proficiency test development based on a report prepared by the Korean Institute for Curriculum and Evaluation, which was to be submitted to the Ministry of Education, entitled, "Research report of English education reform to enhance national competitiveness in the global economy." Donga Ilbo predicted that the long-sustained influence of the Test of English for International Communication (TOEIC) in Korea would weaken if a newly developed computer-based test were implemented in language learning facilities at universities. After the TOEFL crisis, Donga Ilbo repeatedly published articles (for example, on January 8 and 24, 2010) demanding governmental involvement in solving the crisis, introducing a detailed timeline for test development, and reporting that the university admission system would accept NEAT scores in 2013.

Donga Ilbo also frequently mentioned for-profit private institutes, hakwon, in relation to NEAT implementation. An article dated February 1, 2011, discussed how private institutes could particularly benefit from the new market provided by NEAT. The article only quoted hakwon representatives, who made statements such as "the current public schools cannot handle English speaking and writing," and "students have no options other than to rely on private education". Regardless of whether the Ministry can successfully reduce expenses for private education, or whether hakwon foresee growth in new business for test preparation, the texts in all the articles related to "profits" for private institutes as well as the "market value" of NEAT. On May 30, 2011, Donga Ilbo published an opinion article regarding the importance of reducing the anxiety of new test consumers and pointed out that the number of people relying on private lessons would decrease if the College Scholastic Ability Test (CSAT) was replaced with NEAT. The title of the article, "Replacing CSAT to normalize English education," reflected an optimistic attitude toward NEAT as both a replacement for the CSAT and a policy tool to address the problems with English education in Korea. Donga Ilbo articles were also related to features of online test enforcement or other technological aspects of item construction and rating and often focused on the meaningfulness of English proficiency testing in terms of egalitarian values and its necessity for Korea.

JoongAng Ilbo included all the issues mentioned in the other publications, including hakwon education, technology, national competitiveness, and utility and also maintained that NEAT would solve the TOEFL crisis. For example, an editorial published on April 12, 2007, titled "TOEFL crisis, let's solve it with a domestic test" explicitly used problem-solving wording. It was argued that a new test was needed, since TOEFL was (putatively) inconvenient for test-users, and that a newly developed domestic test could reduce dependency on TOEFL. A cost-benefit analysis in this spirit was included in an article published the following day, as "a solution to the TOEFL registration crisis." JoongAng Ilbo's coverage also used words associated with "market" value. An article from April 17, 2007, titled "English test, market crisis due to greater demand than supply," suggested that domestic supply for the TOEFL cannot keep up with increasing demand. It stated that some countries with significant demand for the TOEFL, such as 
Japan, China, and Taiwan, had already established their own homegrown English proficiency tests. The article used the concepts of market supply and demand to discuss the usefulness of English proficiency testing. An opinion piece dated August 12, 2007, discussed the testing issues within the frame of market value. It cited the market competition between IBM and Apple during the 1980s, claiming that although Apple had technologically better products, IBM had products that were more commonly used and that the same applies to the market for English tests. It stated that broad usability is an important competitive factor. In this way, the article emphasized the test's market-determined utilitarian value, using terms such as "compatibility," "usability," and "competition standard," which make products and services "compete against each other in the market" and ultimately merge. JoongAng Ilbo also included many articles on test prep education, featuring phrases and headlines such as "private education industry getting bigger," "hakwons expecting benefit and smiling" (January 23, 2008), "hakwons affirming that the number of enrolled students will increase," and "stock values of test prep companies increasing" (January 24, 2008). Most authorities consulted in these articles were private education representatives.

\section{Discourses constructed intertextually}

As the media delivered information on NEAT development, enforcement, and preparation, individual texts organized themselves into a few clear streams of discursive practice. This section explores three such clustered discourses: (1) a technology-embedded discourse claiming that English learning and testing are more meaningful in a technologized environment than in any other context, (2) an economic discourse claiming that NEAT would either win or lose against private education, and (3) a utilitarian discourse claiming that a domestic test is more beneficial than imported tests such as the TOEFL or TOEIC.

\section{Technology-oriented practice: technologization of NEAT}

The concept of technology extends beyond scientific, industrial, or engineering processes and products to a wide range of other areas, including the development and implementation of language proficiency tests. That is, technology is a systematic tool that meets needs, solves problems, and enables the achievement of socioeconomic goals-a body of skills or procedures necessary for human activities. In this respect, a language test can also be considered a form of technology (Madaus, 2001), as it requires systematic knowledge and professional experience in item writing, rating, data analysis, and validation.

All three newspapers overemphasized NEAT's technological aspects and conflated the process of test development, implementation, and preparation into a single technologyoriented discourse event. Terms such as "technological restrictions" were often repeated when judging NEAT's strengths and weaknesses. News articles provided detailed descriptions of the item bank, rater training, scoring rubrics, score reports, and other technical elements related to test-taking, the online system, or policymaking around NEAT. They highlighted the potential for disruption of the test schedule due to errors and delays in test development and implementation. It was argued that a test developed in Korea, "a technologically superior Internet powerhouse," would be more secure than the TOEFL or TOEIC. An IT industry representative described NEAT as a "national certification testing system," relegating test fairness and validity to mere technology issues. 
NEAT-related discourse in the newspapers has been strongly characterized by concern for verbal hygiene (Cameron, 1995, 2000) and McDonaldization (Block, 2002) in the testing business. It has been reported that NEAT is operated entirely through an online database that covers all information and requires actions from test registration to score reporting. The emphasis on the technological aspect gives authority to the practice of teaching-tothe-NEAT. The streamlined discourse of technologization that has been constructed supports the belief that technology is "everything," even in language learning contexts. If the media continues to propagate a technology-driven NEAT discourse, NEAT may eventually act as "a defining technology" that determines the nature of language, language education, and language testing in Korea. In such a discourse, standardized tests are taken for granted as useful, reliable, and even "democratic" tools. However, in fact, their validity varies depending on context and test-users. Discourses on the non-technological aspects of NEAT have been stifled in the media, with the exception of the economic and utilitarian discourse discussed below.

\section{Economic practice: private education in preparation for NEAT}

Beginning with the 2007 TOEFL crisis, each of the newspapers published articles discussing the necessity of a government-led English proficiency test, the timetable for NEAT's development, and other implementation issues from an economic perspective. NEAT coverage shifted to the inevitable private expenditure on English education; eventually, the diffuse texts of NEAT were explicitly integrated to form a dominant discourse driven by concern with the "market." For example, a Chosun Ilbo article dated July 31, 2007 (after the culmination of the TOEFL crisis), which reported that a newly developed NEAT would be launched in 2009, presented a primarily economic argument describing the test as one that would prevent the outflow of national wealth and expecting significant benefits to be newly generated. Every article published by Chosun Ilbo on the topic after 2010 mentioned the private expenditure for education, sustaining a streamlined discourse on economic issues.

Chosun Ilbo, in shaping the economic discourse related to NEAT, did not allow for a wide range of reflections on English proficiency testing in Korea. Articles were often related to the test's financial viability and burden, and Chosun Ilbo seemed to be the most vocal on this topic. Further research needs to examine why the media couched the new test in a narrow economic discourse and did not refer to any other (critical, ecological, postmodern, alternative) discourses of language and testing.

\section{Utilitarian practice: benefits of a new, domestic test}

The news media had continued to construct a NEAT discourse on cost-benefit analysis. From the onset of the 2007 TOEFL crisis, NEAT's utilitarian value was discussed with reference to problems associated with the foreign tests (TOEFL, TOEIC), the necessity of a government-led English test, and the proposed strategies for NEAT implementation. The news media often used quantitative data to calculate profit and cost when debating problems related to the use of conventional tests or the development of a new test. In an article titled "NEAT, internal stability is important" on May 27, 2011, Donga Ilbo asserted NEAT's practicality and interpreted NEAT as a tool to enhance Koreans' English proficiency and thereby their competitiveness in the global economy. An opinion piece 
published in the same newspaper 3 days later similarly claimed that NEAT could promote effective strategies for teaching English and be a national asset in the near future. Terms such as "practicality," "internal stability," "effectiveness," and "asset" were often employed in the analyzed newspapers. In 2011, Donga Ilbo articles emphasized NEAT's functional utility, claiming it should replace the CSAT. The rationale came from the texts of utility: convenience, cost-effectiveness, accessibility, and competitiveness.

JoongAng Ilbo also constructed a utilitarian discourse in a consistent way. An article from September 6, 2010, sets the tone: "NEAT is in development to become a Korean version of the TOEIC-TOEFL." By paralleling the terms "Korean version" and "TOEICTOEFL," the sentence emphasized NEAT's utilitarian value at the national level. In 2007, JoongAng Ilbo compared NEAT with foreign tests such as the TOEIC and TOEFL to place a strong value on the domestic test's public utility; but, as NEAT was under development, the media began to semantically equate NEAT with the TOEIC and TOEFL. An opinion column published on June 1, 2011, incorporated statements and phrases such as "the supremacy of English stays strong" and "NEAT will satisfy everyone from a practicality perspective." JoongAng Ilbo, in its careful shaping of neo-conservative discourse, imprinted the individual and national effectiveness of English use on its readers' minds by using terms such as "supremacy," "competitiveness," and "revolution." The article acknowledges "English supremacy" in its first sentence and "English skills as individual and national competitiveness" in its second sentence; it continues to cite NEAT's advantages, including an abrupt claim that the test is a revolutionary solution to improve Koreans' English proficiency: not only does NEAT make it easier to gain English proficiency, English education policies based on the high-stakes test maximize its practicality and fairness. Donga Ilbo's articles relating to the 2007 TOEFL crisis also employed utilitarian arguments, claiming that, as registering for the TOEFL had become difficult in Korea (especially for those who had not studied abroad), the foreign tests should be replaced with a domestic test that would allow for lower fees and be free for low-income students. In light of this utilitarian emphasis on NEAT's convenience as a tool (for national competitiveness), in a comparison of NEAT versus conventional/foreign tests, it is difficult to establish a non-utilitarian discourses that can embrace difference and diversity issues.

\section{Social structure underlined}

Two social practices related to NEAT coverage will be discussed here. The first one is that of a "technopoly-driven" educational culture (Postman, 1993) - that is, one that transforms the multifaceted elements of language, testing, and education into technologized tools. The second is the normalization of a "teach-to-the-test" culture by maintaining that NEAT can solve the problems of English education and equating NEAT prep with English study as a whole. In perpetuating such discourses, media discourse constructs a test-based educational culture on the belief that test-driven English study can be successful.

\section{Building up a technopoly of English proficiency testing}

English proficiency testing is a technology, as noted, and regarding language testing as neutral and apolitical overlooks the inherent potential for a high-stakes testing industry to grow into a technopoly. NEAT, as a knowledge system and technological solution, was viewed as not merely a tool but also beyond that as a procedural attempt to develop a 
testing society. The news media promoted NEAT as a technological solution to common problems. Highlighting NEAT's problem-solving effectiveness shifted perceptions-people came to view the test not as a tool but as a goal in and of itself. This transformational process, rather than reflecting a transition to a technocracy, had more similarity with the development of a technopoly, different from a technocracy as elaborated by Postman (1993).

In almighty technology, advances in science and technology in turn determine the advancement of social systems (Habermas, 1970, p. 105). Valuing capitalism and scientism, technopolistic worldviews position technology as the equivalent of medieval society's divine authority in daily life and academia (Habermas, 1970, p. 75). In a technology-dominated society, life is fundamentally a matter of technological adjustment-and conversely, technology can solve all emotional, individual, and social problems. Although it has an ambiguous ideological background, technology has become a dominant cultural philosophy; its ability to suppress ethics and other values makes it an irresistible and powerfully influential ideology (Habermas, 1970, p. 111). In a technopolistic worldview, technology is more than a tool; it shifts the subjects and systems on which individuals and society focus. Thus, by positioning NEAT as a technopolistic solution, media discourse may have jeopardized multiple, potentially more meaningful ways to teach and learn different Englishes in different contexts.

After the 2007 TOEFL crisis, the Korean media had the opportunity to pose many ethical and sociopolitical questions relating to English language learning, testing, and policymaking. Instead, the media's depiction of the crisis was narrow and biased, as they often represented the NEAT knowledge system from a technological perspective, reducing most inquiries to Q\&As in educational technology. There was no fuel for debate among the various interest groups involved on the significance of testing problems. The portrayal of NEAT users in the media is reminiscent of Marcuse's (1964) One-Dimensional Man. He described modern society as composed of people with a false consciousness, who use technology to live within the constraints of existing structures, by consuming and producing a language that is critically limited. That is, he claimed that capitalism, which advocates scientific management techniques and rational production systems, has raised the standard of living for modern people but in turn deprived them of expressive language, not allowing them to ask who they are. Complicated and conflicting discourses are unavoidable when developing a new test as a high-stakes policy tool and incorporating it into the variety of decision-making processes on the teaching and use of English in the Korean context. In the news articles considered here, however, test-takers' and learners' views seemed to be neutralized-surrounded and penetrated by a great mechanical tool: NEAT. It is therefore difficult to manifest a critical position related to NEAT as a technopolistic element unless other arguments are collected. In this way, a hegemonic NEAT-based technopoly may later expand its influence not only to the news media but also to daily life and public education.

\section{Justifying a "teach-to-the-test" culture}

In the Korean media, NEAT was presented as a fine commodity and NEAT preparation idealized as a meaningful social practice. Previous modes of English study were cast as flawed, and NEAT was presented as a new and improved form of English study. The focus on speaking and writing in NEAT, as against the CSAT or TOEIC, was often cited in the cost-benefit discourse. The news articles claim that NEAT was developed 
to transform a (putatively) obsolete English-learning culture characterized by less effective methods and in so doing unite possibly diverse pedagogical aims and channels into one single package.

The economic discourse in NEAT coverage in particular seems to support a test preparation culture that prioritizes monetary value. For example, Chosun Ilbo argued that the TOEFL crisis should be solved through supply-and-demand market principles and supported its position by quoting some representatives of private education. Other news media repeatedly discussed issues of expenses related to test development, registration, preparation, or private education expenditure, including outflow of national wealth, the role of other domestic tests, and whether governments should join together to develop a test to reduce private education expenditure. Chosun Ilbo also assigned a clear economic value to the test and to the associated practice of teaching to the test. From a test-taker's perspective, however, no change would occur: they must study for a big test, regardless of whether it is newly developed or already established, imported, or indigenous. All principal agents in education, including students and schoolteachers, were thus portrayed as "marketized" objects of testing.

As the news media compared domestic and imported high-stakes tests from the perspectives of "convenience," "effectiveness," and "profitability," they excluded from the discussion small-scale (e.g., school-based) or specific-purpose testing contexts, in which a high-stakes test may not act as a gatekeeper. In other words, the utilitarian discourse rigidly solidifies NEAT-based English study as a cultural form and rejects other competing discourses generated in favor of non-NEAT or other language education environments. If the news media focuses on NEAT's utilitarian benefits and integrates the influence of NEAT on education as a whole, as well as on the knowledge system and linguistic society, NEAT preparation can eventually become established as a strong social practice, again with utilitarian values reinforced. It should be pointed out that hegemonic attitudes to NEAT were not reinforced over time because the media were also split on expansion and suspension of NEAT (Shin \& Cho, 2019). Such a utilitarian discourse underlying pro-NEAT arguments, however, would continue to limit democratic discussions and prompt neo-conservative ones that privileged NEAT as the only way to foster national competitiveness and reduce the social cost of English testing.

Language testing is a social practice (McNamara, 2001). As language proficiency is assessed in a social context, there is no reason to throw out the socially embedded technological, economic, and utilitarian discourses. A test's "perceived" social value determines its use, and NEAT can be practiced within such a discourse. However, if news media do not allow for conflicting and alternative discourses, technopoly and teach-to-the-NEAT culture will be invested with a media imprimatur and become hegemonic social practices.

\section{Conclusion}

This study has analyzed NEAT-related newspaper articles using a CDA framework. It has revealed that the reportage is characterized by a threefold focus on the technological, economic, and utilitarian value of NEAT. Rather than constructing NEAT as "just another testing tool," the media aggressively promoted the establishment of a new knowledge system in which NEAT was positioned as a technopolistic power in itself. The teach-to-the-NEAT culture this entails is also justified at the level of social practice. It was verified that the discourse structure of English learning and testing constructed by the news media developed 
unidirectionally into NEAT, regardless of NEAT's actual goals and implementation. There was media pressure on the new test to resolve the problems with old and supposedly obsolete tests as well as English education as it was conducted. Similar to the existing social practice arising from discourse on the TOEIC (which two million applicants take annually in Korea), if knowledge of English language (learning and testing) is implanted in a NEAT-embedded discourse, it will be difficult to extricate such issues from the hegemonic structure of NEAT.

Areas for further research follow. First, researchers should consider the possibility of a controlled future in which English knowledge and educational activities will narrow with the formation of high-stakes testing culture, and "test scores are artificially inflated to the point of questionable validity, by teaching to the tests" (Shohamy, 2001, p. 109). Newspaper articles on NEAT, especially when the rationale for the use of the new homegrown test was being discussed, often appeared to picture such a "brave new world" (Huxley, 1998), but it should be noted that the vaunted NEAT assesses only a limited range of English proficiency. High-stakes testing can "affect education and forces students to cram for tests.... In this way, it uses encroaching power, narrowing the width of learning" (Spolsky, 1998, p. 2). The corresponding shift in cultural focus may neglect, inter alia, the importance of rapport between teachers and students, collaborative work among teachers, and the crucial communicative elements/contexts of improvisation, negotiation of meaning, and everyday unplanned talk. If the belief is diffused that the technologized discourse appearing in NEAT preparation materials is to be preferentially produced and consumed (as frequently seen in the media analyzed here), that is, if NEAT becomes firmly accepted as a means of change in a new linguistic marketplace, what is taught and learned will soon narrow. Researchers should look at whether students' academic achievement, language proficiency, and beliefs and attitudes toward learning have eroded because of media pressure, the technopolistic system, or teach-to-the-test culture.

Second, it is important that researchers continue to inquire into how the media help shape discourse on English learning and testing and how the discourse is changing. The media can instigate a transformation of uncertain information into institutionalized knowledge, which in turn could reshape long-established customs. This study has explored the production and reproduction of certain media texts generated to affect the public in everyday life; however, it did not investigate the transmission and consumption of the texts in discursive practice, for example, from interactions between genres and styles. The interpretation of government documents in the media leads to a reproduction of part of the policy text. Original policy texts presenting the mandate for test development need to be collected and compared with related texts in different genres (e.g., in advertisements).

Finally, the features of "democratic" test development (and administration) need to be explored. As test development is often guided or regulated politically (Shohamy, 2001) and the interests of certain stakeholders become explicit, only very limited information is shared in public. In such situations, extensive opinions are not collected from all walks of life, and the issues to be debated are quickly determined through a top-down decision-making procedure. Thus, the media and private institutions are able to control rumors surrounding the testing environment. Undemocratic practices related to a newly constructed high-stakes test limit public agency by simply claiming that the establishment of relevant education is possible only through preparation for and use of 
the promoted test. Researchers should face the reality that media discourse has often gone beyond exaggeration and distortion to produce more or less threatening educational environments. It is necessary to ask questions about ethical responsibilities or democratic principles to mitigate disruption of language testing in society.

This study has highlighted the representation of NEAT reportage by the media in power and NEAT as a technology of an oppressive power. However, power is not monolithic but more diffuse in nature. Power relations and mobility are unavoidable, and as Foucault (1980) pointed out, alongside power also exists resistance. Thus, further research does not have to advocate dismantling the power of testing or replacing one test with another. As such, the simultaneous distribution of different tests could be planned, with conventionally constructed big tests still operating and with the transformative power structure of testing rearranged. Nor do media rule the world unilaterally. Media and academia are complex sites of complicity and resistance. Alternative discourses of resistance and diversity need to be voiced by academia if the media continue to promote conventional or power-serving views.

\section{Endnotes}

${ }^{1}$ When the Educational Testing Service (ETS) had reduced the number of TOEFL-iBT testing spaces in Korea, excessive demand for test registration outstripped the available space. The media reported on the TOEFL-taking situation, desperate test-takers, and the usefulness of TOEFL and other English proficiency tests.

${ }^{2}$ Although 14 articles in Kyunghyang Shinmun and 7 articles in Hankyoreh were also examined, they are excluded from this analysis because they showed trends and texts similar to those of the news already analyzed here.

${ }^{3}$ The Ministry of Education changed its name to the "Ministry of Education, Science, and Technology" on February 25, 2008.

\section{Abbreviations}

CDA: Critical discourse analysis; CSAT: College Scholastic Ability Test; ETS: Educational Testing Service; NCLB: No Child Left Behind; NEAT: National English Ability Test; TOEFL: Test of English as a Foreign Language; TOEIC: Test of English for International Communication

Acknowledgements

Not Applicable

Funding

This study was supported by a grant from the National Research Council for Economic, Humanities, and Social Sciences in Korea.

Availability of data and materials

Data and material are available in Korean.

Authors' contributions

The author is the sole contributor to this research paper. The author read and approved the final manuscript.

Authors' information

Dongil Shin, Ph.D., is a professor of the Department of English Language and Literature, Chung-Ang University, Seoul, Korea. After completing his doctorate degree at University of Illinois at Urbana-Champaign, he has taught and researched language testing, discourse analysis, multilingual societies and language policy, mostly in Korean contexts.

Competing interests

The author declares that he has no competing interests. 
Received: 15 January 2019 Accepted: 7 March 2019

\section{Published online: 03 April 2019}

\section{References}

Bachman, L. F., \& Palmer, A. S. (2010). Language assessment in practice: Developing language assessments and justifying their use in the real world. Oxford: Oxford University Press.

Baker, P., Gabrielatos, C., \& McEnery, T. (2013). Sketching Muslims: A corpus driven analysis of representations around the word "Muslim" in the British Press 1998-2009. Applied Linguistics, 34(3), 255-278. https://doi.org/10.1093/applin/arms048.

Blackledge, A. (2005). Discourse and power in a multilingual world. Amsterdam: John Benjamins Publishing.

Block, D. (2002). "McCommunication:" A problem in the frame of SLA. In D. Block \& D. Cameron (Eds.), Globalization and language teaching (pp. 117-133). London: Routledge.

Block, D., Gray, J., \& Holborow, M. (2012). Neoliberalism and applied linguistics. New York: Routledge.

Breeze, R. (2011). Critical discourse analysis and its critics. Pragmatics, 21(4), 493-525.

Cameron, D. (1995). Verbal hygiene. London: Routledge.

Cameron, D. (2000). Good to talk: Living and working in a communication culture. London: Sage Publications.

Cheng, W. (2013). Corpus-based linguistic approaches to critical discourse analysis. In C. Chapelle (Ed.), The encyclopedia of applied linquistics (pp. 1353-1360). Oxford: Blackwell.

Crawford, J. (2004). Educating English learners. Language diversity in the classroom. Los Angeles: Bilingual Educational Services.

Fairclough, N. (1992). Discourse and social practice. Cambridge: Polity Press.

Fairclough, N. (1995). Media discourse. London: Edward Arnold.

Fairclough, N. (2005). Critical discourse analysis. London: Longman.

Foucault, M. (1975). Discipline and punish: The birth of the prison. New York: Vintage Books.

Foucault, M. (1980). Power/knowledge: Selected interviews and other writings, 1972-1977. New York: Pantheon Books.

Fulcher, G. (2009). Test use and political philosophy. Annual Review of Applied Linguistics, 29, 3-20. https://doi.org/10.1017/ S0267190509090023.

Fulcher, G., \& Davidson, F. (2007). Language testing and assessment. London \& New York: Routledge.

Gonzalez-Carriedo, R. (2014). Ideologies of the press in regard to English language learners: A case study of two newspapers in Arizona. Critical Inquiry in Lanquage Studies, 11(2), 121-149.

Habermas, J. (1970). Toward a rational society. Boston: Beacon Press.

Hamp-Lyons, L. (2000). Social, professional and individual responsibility in language testing. System, 28(4), 579-591. https:// doi.org/10.1016/50346-251X(00)00039-7.

Huxley, A. (1998). Brave new world. New York: HarperCollins Publishers.

Kane, M. (2001). Current concerns in validity theory. Journal of Educational Measurement, 38(4), 319-342. https://doi.org/10. $1111 / j .1745-3984.2001 . t b 01130 . x$.

Lee, H., \& Lee, K. (2016). An analysis of the failure(s) of South Korea's National English Ability Test. Asia-Pacific Education Researcher, 25(5-6), 827-834.

Li, J. (2009). Intertextuality and national identity: Discourse of national conflicts in daily newspapers in the United States and China. Discourse \& Society, 20(1), 85-121. https://doi.org/10.1177/0957926508097096.

Lin, A. (2014). Critical discourse analysis in applied linguistics: A methodological review. Annual Review of Applied Linguistics, 34, 213-232. https://doi.org/10.1017/S0267190514000087.

Madaus, G. (2001). Educational testing as a technology. NBETPP Statements, 2(1), 1-12.

Marcuse, H. (1964). One-dimensional man. Boston: Beacon.

McDonald, L. (2014). Think tanks and the media: How the conservative movement gained entry into the education policy arena. Education Policy, 28(6), 845-880.

McNamara, T. F. (2001). Language assessment as social practice: Challenges for research. Language Testing, 18(4), 333-349. https://doi.org/10.1177/026553220101800402

McNamara, T. F., \& Roever, C. (2006). Language testing: The social dimension. London: Blackwell Publishing.

Menken, K. (2008). High-stake tests as de facto language education policies. In E. Shohamy \& H. Hornberger (Eds.), Encyclopedia of language and education: Language and assessment (Vol. 7, 2nd ed., pp. 401-413). New York: Springer.

Messick, S. (1989). Validity. In R. L. Linn (Ed.), Educational measurement (3rd ed., pp. 13-103). New York: American Council on Education \& Macmillan.

Postman, N. (1993). Technopoly: The surrender of culture to technology. New York: Vintage Books.

Ritzer, G. (2000). The McDonaldization of society: An investigation into the changing character of contemporary social life. Thousand Oaks: Pine Forge Press.

Shin, D., \& Cho, E. (2019). Discursive conflicts in news media and the suspension of a government-led test of English in Korea. Manuscript submitted for publication.

Shin, D. (2012). TOEFL daylaney kwanhan sinmunkisabunsek: Bipanjeokdamlonbunseokul kibanuro [Analyzing newspaper articles on TOEFL Crisis through critical discourse analysis]. Foreign Languages Education, 19(1),187-210.

Shohamy, E. (2001). The power of tests: A critical perspective on the uses of lanquage tests. London: Pearson.

Spolsky, B. (1998). Sociolinguistics. Oxford: Oxford University Press.

Tan, P. K. W., \& Rubdy, R. (Eds.). (2008). Language as commodity: Global structures, local marketplaces. New York: Continuum International Publishing.

van Dijk, T. A. (Ed.). (1997). Discourse as social interaction. New York: Sage.

Whitehead, G. (2016). The rise and fall of the National English Ability Test: Exploring the perspectives of Korean high school English teachers. Asian EFL Journal, 18(4), 124-155.

Widdowson, H. (1998). The theory and practice of critical discourse analysis. Applied Linguistics, 19(1), 136-151.

Widdowson, H. (2005). Text, context, pretext: Critical issues in discourse analysis. Oxford: Blackwell.

Yemini, M., \& Gordon, N. (2017). Media representations of national and international standardized testing in the Israeli education system. Discourse: Studies in the Cultural Politics of Education, 38(2), 262-276. 